\title{
Caracterização física e físico-química de frutos de diferentes genótipos de bacurizeiro (Platonia insignis Mart.)
}

\author{
Physical and physico-chemical characterization of fruits from \\ different genotypes of bacuri (Platonia insignis Mart.)
}

\author{
Larissa Pereira AGUIAR ${ }^{1}$, Raimundo Wilane de FIGUEIREDO ${ }^{2 *}$, Ricardo Elesbão ALVES ${ }^{3}$, \\ Geraldo Arraes MAIA ${ }^{2}$, Valdomiro Aurélio Barbosa de SOUZA ${ }^{4}$
}

\section{Resumo}

O objetivo deste trabalho foi avaliar a qualidade de frutos de diferentes genótipos de bacurizeiro provenientes do Estado do Piauí, região Meio Norte do Brasil. Frutos maduros foram colhidos de 17 genótipos diretamente do solo, conduzidos à Embrapa Meio Norte, Teresina - PI, onde foram realizadas análises físicas de peso total, comprimento, diâmetro, rendimento de polpa e número de sementes. A polpa foi extraída de cada genótipo, dividida em três lotes iguais, onde cada lote representou uma repetição, foi acondicionada em sacos plásticos, homogeneizada, congelada a $-20^{\circ} \mathrm{C}$ e transportada via terrestre, sob refrigeração, para o Laboratório de Fisiologia e Tecnologia Pós-colheita da Embrapa Agroindústria Tropical, em Fortaleza - CE, onde foram realizadas as análises físico-químicas de sólidos solúveis, acidez, pH e relação SST/ATT. O delineamento utilizado foi inteiramente casualizado (DIC) pelo teste de Tukey a 5\%, quando foi constatada a significância pelo teste $F$. Os genótipos apresentaram diferenças significativas $(\mathrm{p}<0,05)$ para todas as análises realizadas. Para o consumo in natura, destacaram-se as matrizes M6, M14, M22 e M23, por apresentarem características de um bom rendimento de polpa e teores de SST e relação SST/ATT superiores às demais matrizes. Em relação ao rendimento industrial, os maiores foram observados para as matrizes M5, M14 e M21, considerando-se as características de percentagem de polpa e SST superiores à média desse estudo.

Palavras-chave: caracterização; genótipos; bacuri.

\begin{abstract}
The purpose of this work was to evaluate the quality of bacuri from different genotypes proceeding from the state of Piauí, mid-northern region of Brazil. Mature fruits from 17 different genotypes were harvested directly from the ground, transported to Embrapa Mid-North, in Teresina, Piauí, Brazil, and the following physical analyses were performed: total weight, length, diameter, pulp yield, and number of seeds. The pulp was extracted from each genotype and divided in three lots, where each lot represented a repetition, packed in plastic bags, homogenized, frozen at $-20^{\circ} \mathrm{C}$ and transported to the Postharvest Physiology and Technology Laboratory at Embrapa Tropical Agroindustry, in Fortaleza, Ceará, Brazil. The following physical-chemical analyses were performed: soluble solids, acidity, pH and TSS/TTA ratio. A completely randomized design was used, with the Tukey test at a $5 \%$ level, once the significance was verified by the $F$ test. The genotypes presented significant differences $(\mathrm{p}<0.05)$ in all the analyses performed. For fresh consumption, matrixes M6, M14, M22 and M23 presented a good yield of pulp and values of TSS and TSS/TTA ratio higher than the others matrixes. The highest industrial yields were observed for matrixes M5, M14, and M21, taking into account pulp percentage and TSS, which were considered higher than the average in this study.
\end{abstract}

Keywords: characterization; genotypes; bacuri.

\section{Introdução}

O bacurizeiro pertence à família Clusiaceae, subfamília Clusioideae, gênero Platonia Mart. e a espécie é classificada como Platonia insignis Mart (BRAGA, 1976).

O bacuri é um fruto do tamanho de uma laranja, redondo, com casca grossa e de cor amarelo-citrina, contendo polpa viscosa e muito saborosa. Quando maduro, exala um perfume suave e fragrante, que se assemelha ao jasmim (FONSECA, 1954).

Na maior parte das árvores, os frutos caem quando estão maduros, de maneira que a colheita consiste em recolhê-los do solo (FAO, 1987). Teixeira et al. (2005) observaram que os frutos de todos os estádios de maturação do bacuri apresentam, a partir do terceiro dia de colheita, comportamento respiratório não climatérico, com os frutos "de vez" apresentando maior taxa de produção de $\mathrm{CO}_{2}$ até o quarto dia de armazenamento $\left(177,63 \mathrm{mgCO}_{2} \cdot \mathrm{Kg}^{-1} \cdot \mathrm{h}^{-1}\right)$.

Os frutos do bacurizeiro estão entre os mais importantes da Amazônia, pois suas características de odor e sabor os tornam bastante procurados e consumidos pela população local

\footnotetext{
Recebido para publicação em 4/4/2007

Aceito para publicação em 13/3/2008 (002414)

1 Universidade Federal do Ceará - UFC

2 Departamento de Tecnologia de Alimentos, Centro de Ciências Agrárias, Universidade Federal do Ceará - UFC, Campus do Pici, s/n, CP 12168, CEP 60356-000,

Fortaleza - CE, Brasil, E-mail: figueira@ufc.br

3 Embrapa Agroindústria Tropical, Fortaleza - CE, Brasil, E-mail: elesbao@cnpat.embrapa.br

${ }^{4}$ Embrapa Meio Norte, Teresina - PI, Brasil

${ }^{*}$ A quem a correspondência deve ser enviada
} 
(FERREIRA et al., 1987). Sua importância econômica nas regiões Norte e Nordeste do Brasil ocorre devido ao grande consumo pela população local, tanto in natura, como integrante de sorvetes, cremes néctares, refrescos, compotas e geléias (VILLACHICA et al., 1996).

A região do Meio Norte caracteriza-se pela diversidade de ecossistemas e pela biodiversidade, com destaque para as espécies frutíferas nativas; muitas delas com elevado valor econômico tanto para o mercado de frutas in natura como para o mercado de frutas processadas. Dentre as fruteiras nativas de elevado valor sócio-econômico merece destaque especial o bacurizeiro. Essa espécie já é amplamente utilizada pelas populações locais, podendo também ser encontrada em feiras livres, mercados e supermercados de várias cidades, inclusive das capitais (ALVES et al., 2000; LEDERMAN et al., 2000; SOUZA et al., 2000).

A produção de bacuri é comercializada principalmente na Central de Abastecimento do Pará S.A. (CEASA) e feiras livres de Belém - PA, São Luís - MA e Teresina - PI, e não tem sido suficiente para atender à demanda crescente do mercado consumidor dessas capitais. Na forma de polpa congelada, a comercialização é feita principalmente nas grandes redes de supermercados dessas capitais a preços superiores aos de outras frutas tropicais como o cupuaçu, o cajá, a goiaba e a graviola, por exemplo. Portanto, a médio ou longo prazo, essa espécie pode se estabelecer como uma nova e excelente alternativa para os mercados interno e externo de frutas exóticas (SOUZA et al., 2001).

Esse trabalho teve por objetivo realizar a caracterização física e físico-química de frutos de bacuri coletados de 17 genótipos nativos da região do Meio Norte do Brasil.

\section{Material e métodos}

Os frutos foram colhidos em estádio maduro de 17 genótipos diferentes de plantas nativas de bacurizeiro, previamente identificadas e localizadas nas comunidades de Monte Alegre (M11PP5, M14PP5, M16PP5, M17PP5, M18PP5, M19PP5, M21PP5, M22PP5, M23PP5 e M25PP5) e de Pau D'Arco (M1PI, M2PI, M3PI, M4PI, M5PI, M6PI e M7PI), município de Barras, a $124 \mathrm{~km}$ de Teresina, Piauí, região Meio Norte. A colheita manual dos frutos foi realizada entre os dias 03 e 06 de fevereiro de 2005 e os frutos foram conduzidos imediatamente à sede da Embrapa Meio Norte em Teresina - PI para a realização de análises físicas. O número de frutos por genótipo oscilou entre 20 e 36, variando com a produtividade da planta, tendo sido empregados 20 frutos de cada genótipo e analisados individualmente. A polpa foi extraída manualmente dos frutos de cada genótipo, com o auxílio de facas e tesouras, e os frutos foram divididos em três lotes iguais, onde cada lote representou uma repetição, a polpa foi acondicionada em sacos plásticos, homogeneizada, congelada a $-20{ }^{\circ} \mathrm{C}$ e transportada via terrestre, sob refrigeração, para o Laboratório de Fisiologia e Tecnologia Póscolheita da Embrapa Agroindústria Tropical, em Fortaleza - CE, onde foram realizadas as análises físico-químicas. As amostras das respectivas polpas permaneceram armazenadas à temperatura de $-20^{\circ} \mathrm{C}$ até o início das análises.

\subsection{Análises físicas}

As análises físicas foram realizadas através do peso total, comprimento e diâmetro, rendimento de polpa e número de sementes.

\subsection{Análises físico-químicas}

A determinação do teor de sólidos solúveis totais (SST) foi realizada após filtração da polpa diluída 1:5 (p/p) em papel de filtro. Utilizou-se refratômetro digital (ATAGO PR-101) com leitura direta de acordo com a metodologia recomendada pela AOAC (1992). A acidez total titulável (ATT) foi determinada por titulação com solução de $\mathrm{NaOH}(0,1 \mathrm{~N})$ até pH 8,1 em titulador automático Mettler, modelo DL 12. Utilizou-se para a determinação de ATT $0,5 \mathrm{~g}$ de polpa homogeneizada com $50 \mathrm{~mL}$ de água destilada. Os resultados foram expressos em percentagem de ácido cítrico, segundo metodologia do IAL (1985). A relação SST/ATT foi obtida pelo quociente entre SST e ATT. O pH foi medido diretamente na polpa, logo após o processamento, utilizando um potenciômetro (Mettler, modelo DL 12), aferido com tampões de pH 4 e 7, conforme AOAC (1992).

O delineamento experimental foi inteiramente casualizado, utilizando-se os materiais genéticos como tratamentos, com 3 repetições em cada tratamento. Após a análise de variância, quando constatada a significância pelo teste $F$, as médias foram comparadas pelo teste de Tukey a 5\% de probabilidade.

\section{Resultados e discussão}

Para todas as características estudadas, a análise de variância revelou diferenças estatísticas entre os tratamentos (genótipos) pelo teste $F$.

\subsection{Análises físicas}

Houve uma grande variação nos pesos totais dos genótipos de bacurizeiros, de 118,17 a 503,26 g, com média de 275,60 g. Conforme análise estatística, os genótipos M2 e M19 destacaram-se estatisticamente dos demais, com resultados de 503,26 e 492,41 g, respectivamente (Figura 1).

A média obtida para os bacuris avaliados, 275,60 g, é superior à encontrada por Pechnik e Siqueira (1950), que relataram que o fruto pesa em média $250 \mathrm{~g}$. Teixeira (2000), em estudo com frutos do bacurizeiro adquiridos na Central de Abastecimento do Piauí S. A. (CEASA) de Teresina, obteve peso médio de $189,18 \mathrm{~g}$.

Santos (1982) relatou peso médio dos frutos de $326,17 \mathrm{~g}$, com amplitude de 210 a $550 \mathrm{~g}$ em bacuris provenientes da cidade de Amarante (PI). Souza et al. (2001) em recente estudo com diferentes genótipos de bacurizeiro da região do Meio Norte (MA e PI), observou médias de 351,26 g para frutos oriundos do Estado do Piauí e 300,58 g para os frutos do Estado do Maranhão, com média geral de 352,92 g.

O peso médio é uma característica importante dentre os aspectos físicos dos frutos, no entanto, não é essencial para o mercado de frutos in natura, visto que o consumidor visa ou- 
tras singularidades, tais como: aparência externa, cor, firmeza, aroma, sabor, etc.

O comprimento oscilou entre 61,51 e 128,21 mm. De acordo com a Figura 2, os genótipos M7, M11 e M25 foram estatisticamente superiores aos demais, com médias de 124,31, 128,21 e $123,45 \mathrm{~mm}$, respectivamente.

Villachica et al. (1996) relatam valores inferiores, de 55 a $105 \mathrm{~mm}$. Souza et al. (1996) e Teixeira (2000) obtiveram valores similares aos observados nesse trabalho, de 70 a $150 \mathrm{~mm}$ de comprimento.

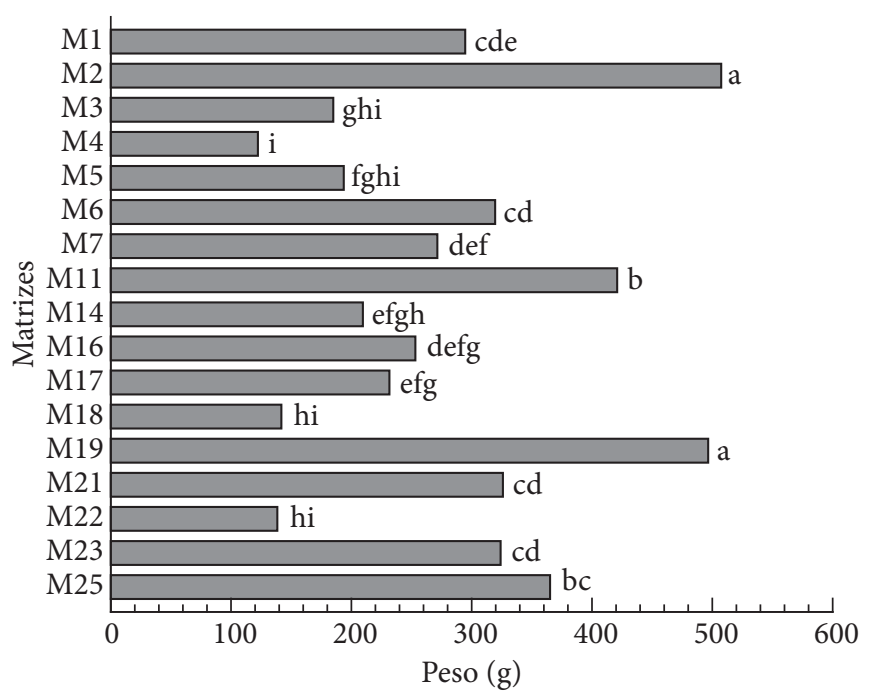

Figura 1. Peso total (g) de frutos do bacurizeiro oriundos da região do Meio Norte, 2005. Médias na vertical seguidas pela mesma letra não diferem entre si pelo teste de Tukey a $5 \%$ de probabilidade, com coeficiente de variação de 25,53\%.

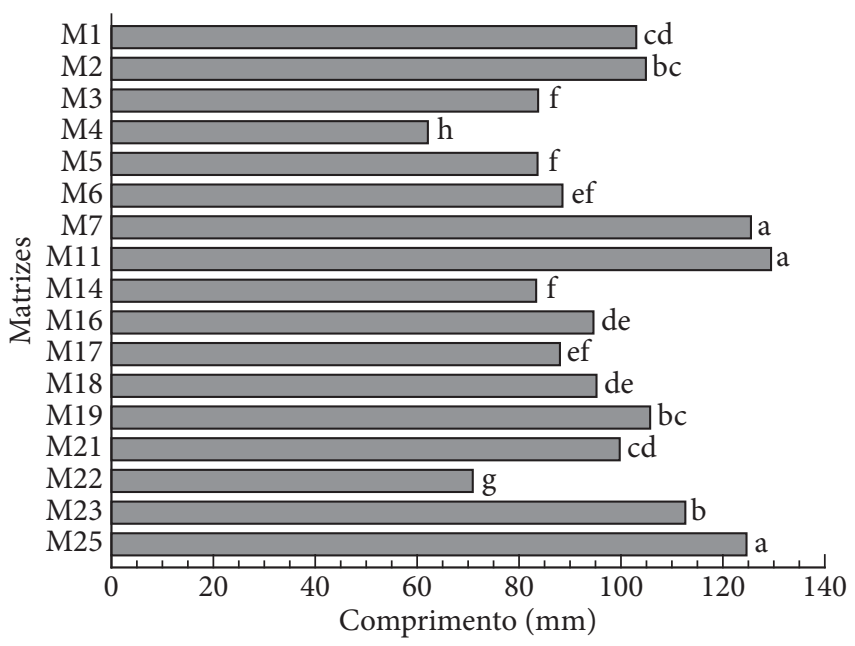

Figura 2. Comprimento $(\mathrm{mm})$ de frutos do bacurizeiro oriundos da região do Meio Norte. Médias na vertical seguidas pela mesma letra não diferem entre si pelo teste de Tukey a $5 \%$ de probabilidade, com coeficiente de variação de $8,01 \%$.
Souza et al. (2001) trabalhando com 26 genótipos de bacuris oriundos da região do Meio Norte (Maranhão e Piauí) encontraram resultados de 77,8 a 119,70 mm, também próximos aos obtidos nesse trabalho.

Na Figura 3, observa-se que o diâmetro variou de 57,52 a 95,01 mm com destaque para os genótipos M2 e M19, que não diferiram estatisticamente, e que apresentaram valores de 92,59 e $95,01 \mathrm{~mm}$, respectivamente.

Teixeira (2000) observou variações de 67,1 a 70,4 mm para frutos obtidos do Estado do Piauí. Souza et al. (2001) constataram variações de 65,5 a 93,0 mm para os frutos oriundos dos Estados do Piauí e Maranhão. Ambas as faixas encontradas foram menores que as do presente trabalho.

Os diâmetros encontrados, em geral, apresentaram valores inferiores em relação aos comprimentos, embora em muitos materiais genéticos esses valores estejam próximos, dando aos frutos do bacurizeiro formas redondas, ovóides ou subglobosas.

Teixeira (2000) e Mourão e Beltrati (1995) observaram que há uniformidade nas dimensões de frutos provenientes de uma mesma árvore, o que demonstra que são caracteres bem fixados geneticamente.

A determinação da percentagem de polpa nos diferentes genótipos de bacurizeiro, representada na Figura 4, revelou uma variação de 11,69 a 22,21\%. Deve-se destacar o genótipo M14, que obteve o máximo rendimento, ou seja, 22,21\%, não diferindo estatisticamente dos genótipos M2, M3, M4, M5, M6, M17, M18, M21, M22 e M23.

Carvalho e Muller (1996), Ferreira et al. (1987), Moraes et al. (1994) e Mourão (1992) relataram de 10 a 13\% de rendimento de polpa, Teixeira (2000) relatou de 16,29 a 18,35\% e Souza et al. (2001) obtiveram de 13,79 a 15,95\% de polpa.

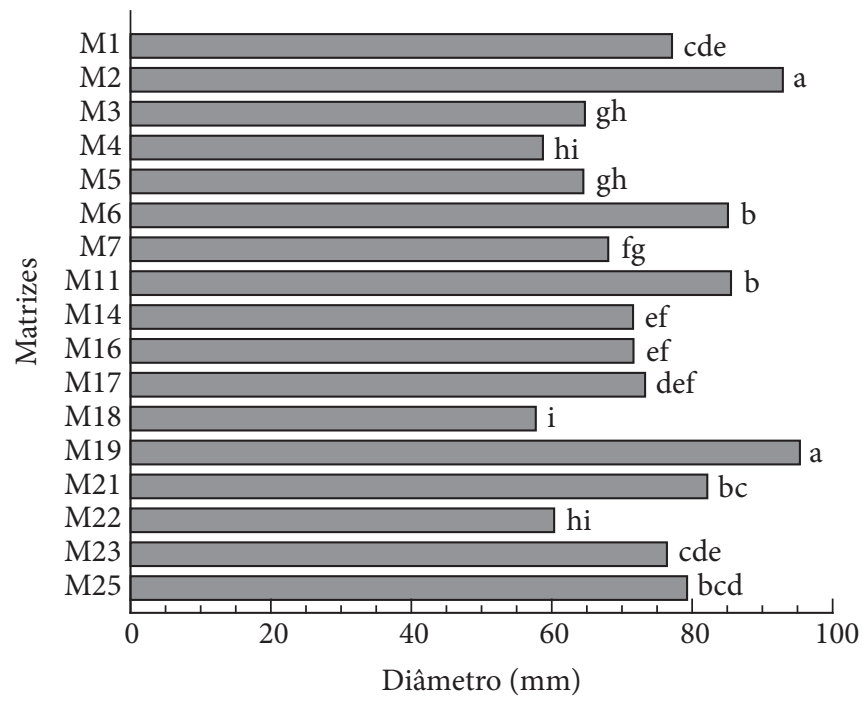

Figura 3. Diâmetro (mm) de frutos do bacurizeiro oriundos da região do Meio Norte. Médias na vertical seguidas pela mesma letra não diferem entre si pelo teste de Tukey a 5\% de probabilidade, com coeficiente de variação de $7,49 \%$. 
O genótipo M11 apresentou o maior número de sementes, ou seja, 3 (Figura 5), enquanto que o M3 apresentou o menor, de 1,15 sementes por fruto.

Souza et al. (2001) observaram 1,96 a 3,82 sementes por fruto provenientes dos Estados do Piauí e Maranhão, resultados superiores aos encontrados nesse estudo. Ainda segundo Souza et al. (2001), frutos mais arredondados tendem a apresentar menos sementes e frutos com maior número de sementes, em geral, produzem menos secções partenocárpicas.

\subsection{Análises físico-químicas}

O teor de sólidos solúveis totais variou de 9,30 a 15,09 ${ }^{\circ} \mathrm{Brix}$ (Figura 6).

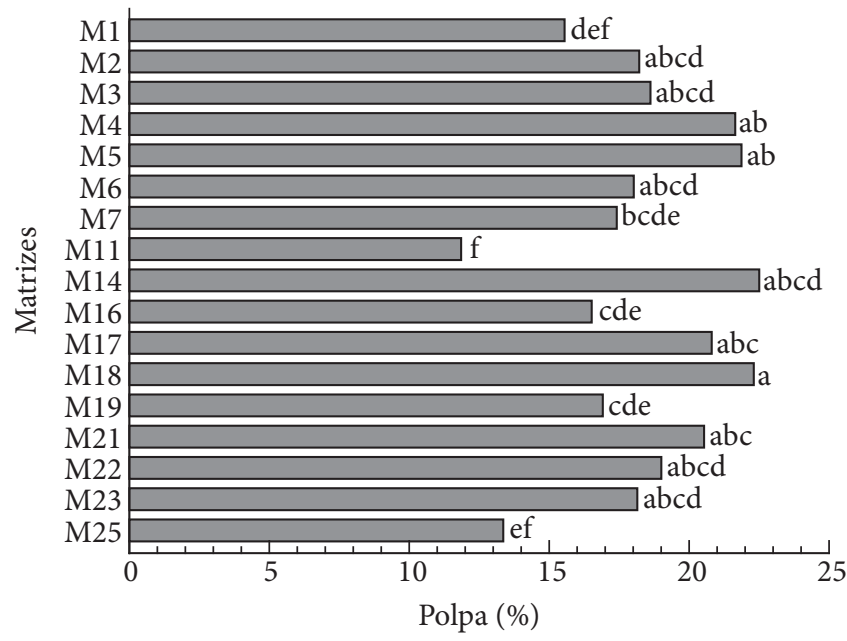

Figura 4. Rendimento de polpa (\%) de frutos do bacurizeiro oriundos da região do Meio Norte. Médias na vertical seguidas pela mesma letra não diferem entre si pelo teste de Tukey a $5 \%$ de probabilidade, com coeficiente de variação de 19,39\%.

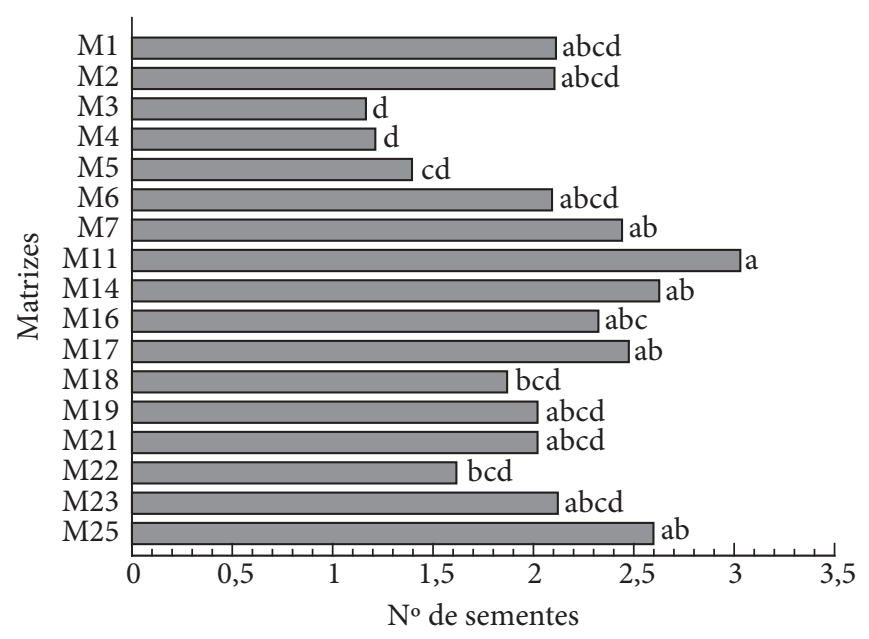

Figura 5. Número de sementes dos frutos do bacurizeiro oriundos da região do Meio Norte. Médias na vertical seguidas pela mesma letra não diferem entre si pelo teste de Tukey a $5 \%$ de probabilidade, com coeficiente de variação de $38,60 \%$.
Os valores encontrados são inferiores aos apresentados por Campos et al. (1951), Santos (1982), Guimarães et al. (1992), Villachica et al. (1996), Teixeira (2000) e Bezerra (2003), que relataram 19,$10 ; 19,10 ; 18,73 ; 16,40 ; 16,80$ e $18,10{ }^{\circ}$ Brix, respectivamente.

A acidez total titulável não se apresentou de forma homogênea, constatando-se uma grande variação entre os genótipos analisados (Figura 7).

O fruto mais ácido foi o do genótipo M1 (3,09\% de ácido cítrico), seguido por M2, M3 e M5, com valores médios de 2,27; 2,54 e 2,20\% de ácido cítrico, respectivamente. Contrariamente, os genótipos M11, M14 e M23 tiveram as menores médias 0,39; 0,76 e $0,80 \%$, respectivamente.

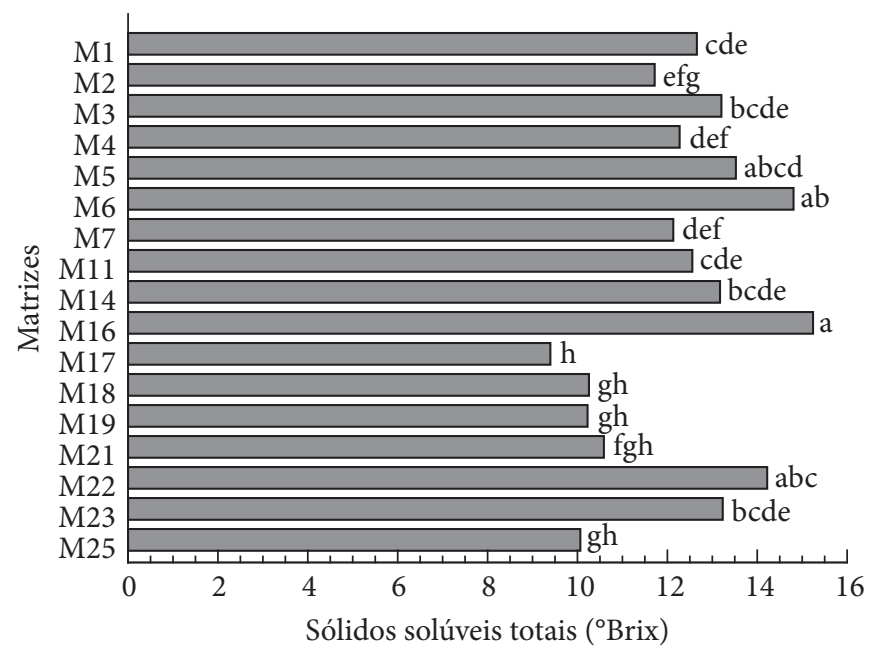

Figura 6. Sólidos solúveis totais ( ${ }^{\circ}$ Brix) de frutos do bacurizeiro oriundos da região do Meio Norte. Médias na vertical seguidas pela mesma letra não diferem entre si pelo teste de Tukey a $5 \%$ de probabilidade, com coeficiente de variação de $4,61 \%$.

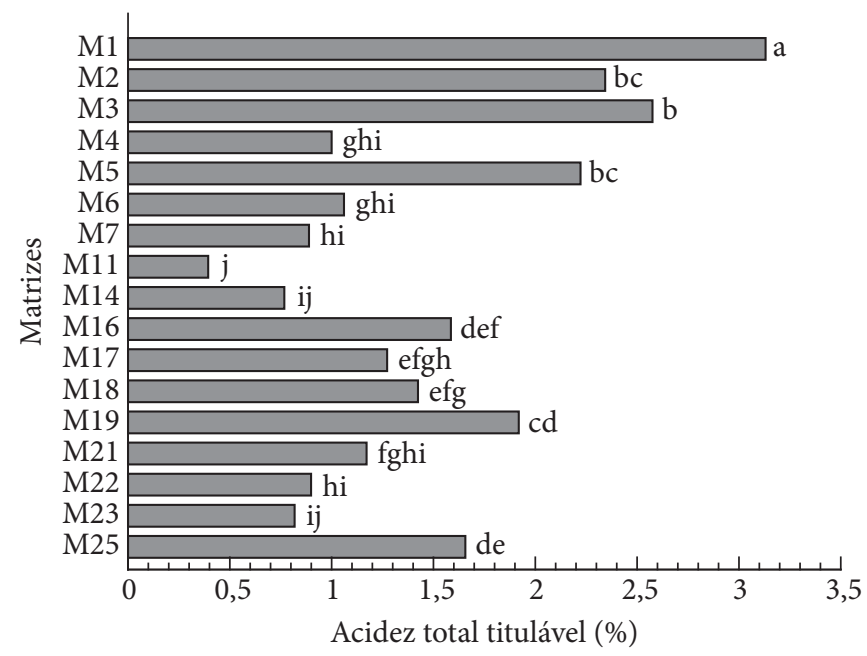

Figura 7. Acidez total titulável (\%) de frutos do bacurizeiro oriundos da região do Meio Norte. Médias na vertical seguidas pela mesma letra não diferem entre si pelo teste de Tukey a $5 \%$ de probabilidade, com coeficiente de variação de $9,88 \%$. 
Esta constatação também foi verificada por Souza et al. (2001), ao realizar essa mesma análise utilizando diferentes germoplasmas de bacuri da região Meio Norte, que apresentou média de 1,37\% semelhante a desse estudo, que é de 1,46\%.

Os resultados encontrados para ATT conferem características apropriadas tanto para o consumo in natura como para o processamento industrial.

O pH variou de 2,76 (M25) a 3,64 (M14) (Figura 8).

Os valores desse estudo estão de acordo com os encontrados na literatura. Santos (1982) relatou um pH de 2,80, Bezerra (2003) de 3,12, Teixeira (2000) de 3,37, Barbosa et al. (1979), Villachica et al. (1996) e Nazaré (2000) de 3,50. Contudo, Almeida e Valsechi (1966) relataram um valor de 5,80, bem superior ao encontrado nesse estudo, que segundo Teixeira (2000) pode ser devido ao uso de frutos em estado avançado de senescência.

De acordo com Villachica et al. (1996), os frutos mais ácidos e os menos doces são empregados na fabricação de sorvetes, sucos, doces em latas, tortas, entre outros. Em relação ao mercado de mesa, pelo sabor diferenciado e quanto ao processamento, por implicar em menores custos à empresa, justificado pela não necessidade da adição de acidulantes para reduzir o $\mathrm{pH}$.

Para a característica SST/ATT houve uma variação enorme. O genótipo M11 apresentou o maior valor, ou seja, 34,26, diferindo estatisticamente de todos os outros, já o M1 obteve o índice mais baixo, de 4,80 (Figura 9). Para o mercado consumidor de frutas frescas e/ou processadas, a relação SST/ATT elevada é desejável. Portanto, o genótipo M11 seria o mais adequado.

Comparando com outros dados da literatura, Barbosa et al. (1979) e Nazaré (2000) com 10,25, Villachica et al. (1996) com 12,06 e Santos (1982) com 15,92 relatam dados semelhantes ou próximos aos desse trabalho. No entanto, Teixeira (2000) e Bezerra (2003) apresentam valores muito superiores, 29,08 e 56,84 , respectivamente.

Segundo Teixeira (2000), o valor da relação SST/ATT para a polpa do bacuri maduro pode ser considerado elevado quando comparado com o de outros frutos, no mesmo estádio de maturação.

A relação SST/ATT é uma das melhores formas de avaliação do sabor dos frutos, a qual ocorre devido, em grande parte, ao balanço de ácidos e açúcares (CHITARRA; CHITARRA, 2005; GONÇALVES et al., 1998).

\section{Conclusões}

Para o consumo in natura, destacam-se as matrizes M6, M14, M22 e M23, por apresentarem características de um bom rendimento de polpa e teores de SST e relação SST/ATT superiores às demais matrizes.

Em relação ao rendimento industrial, os maiores foram observados para as matrizes M5, M14 e M21, considerando-se as características de percentagem de polpa e SST superiores à média desse estudo.

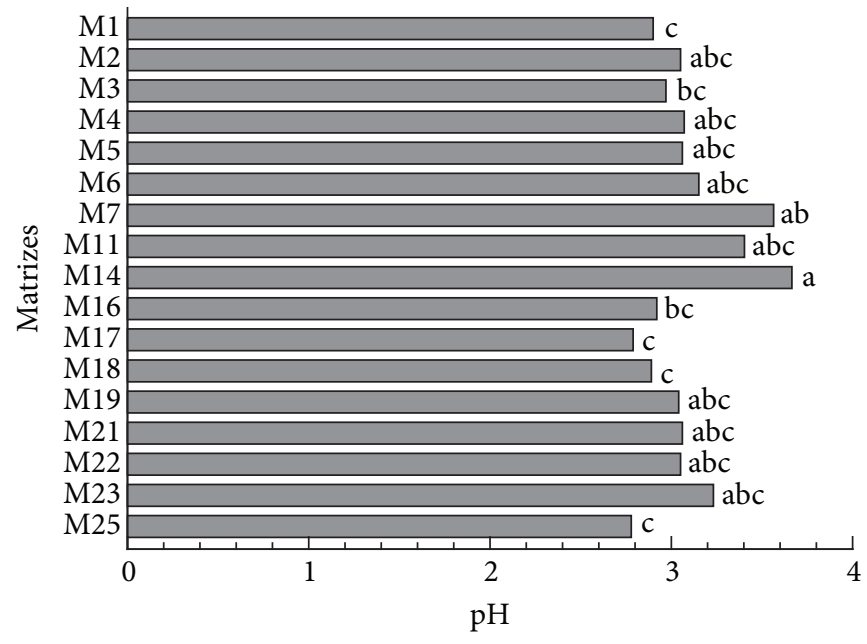

Figura 8. $\mathrm{pH}$ de frutos do bacurizeiro oriundos da região do Meio Norte. Médias na vertical seguidas pela mesma letra não diferem entre si pelo teste de Tukey a $5 \%$ de probabilidade, com coeficiente de variação de $6,80 \%$.

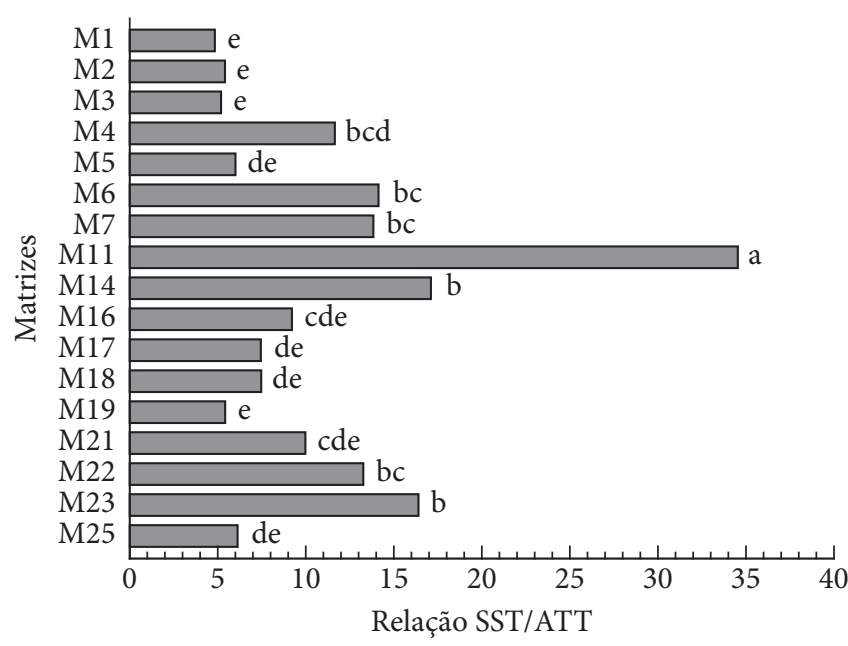

Figura 9. Relação SST/ATT de frutos do bacurizeiro oriundos da região do Meio Norte. Médias na vertical seguidas pela mesma letra não diferem entre si pelo teste de Tukey a $5 \%$ de probabilidade, com coeficiente de variação de $16,86 \%$.

\section{Referências bibliográficas}

ALMEIDA, J. R. de; VALSECHI, O. Guia de composição de frutas. Piracicaba: Instituto Zimotécnico/ESALQ/USP, 1966. p. 21. (Boletim, 21).

ALVES, R. E.; FILGUEIRAS, H. A. C.; MOURA, C. F. H. Caracterização de frutas nativas da América Latina. Jaboticabal: Funep, 2000. 66 p. (Série Frutas Nativas, 9).

AOAC - Association of Official Analytical Chemistry. Official methods of Analysis of the Association of Official Analytical Chemistry. 15 ed. Washington, 1992. 2v.

BARBOSA, W. C.; NAZARÉ, R. F. R. de; NAGATA, I. Estudos físicos e químicos dos frutos: Bacuri (Platonia insignis), cupuaçu (Theobroma grandiflorum) e murici (Byrsonima crassifólia). In: CONGRESSO 
BRASILEIRO DE FRUTICULTURA, 5, 1979. Pelotas, RS. Anais... Pelotas: SBF, 1979, v. 2, p. 797-808.

BEZERRA, G. de S. A. Conservação de polpa de bacuri (Platonia insignis Mart.) por métodos combinados. Fortaleza, 2003, 139 p. Dissertação (Mestrado em Tecnologia de Alimentos) - Universidade Federal do Ceará.

BRAGA, R. Plantas do nordeste especialmente do Ceará. Mossoró: ESAM, 1976. $540 \mathrm{p}$.

CAMPOS, F. A. M.; PECHINIK, E.; SIQUEIRA, R. da. Valor nutritivo de frutas brasileiras: trabalhos e pesquisas. Rio de Janeiro: Instituto de Nutrição, 1951. v. 4, p. 61-171.

CARVALHO, J. E. U. de; MÜLLER, C. H. Propagação do bacurizeiro (Platonia insignis Mart.). Belém: Embrapa - CPATU, 1996. 13 p. (Mimeografado).

Chitarra, A. B.; CHITARrA, M. I. F. Pós-colheita de frutos e hortaliças: fisiologia e manuseio. Lavras: UFLA, 2005. 783 p.

FAO, Organización de las naciones unidas para la agricultura y la alimentación. Especies forestales productoras de frutas y otros alimentos. 3. Ejemplos de América Latina. Roma: SIDA, 1987. p. $167-170$.

FERREIRA, F. R.; FERREIRA, S. A. do N.; CARVALHO, J. E. U. de. Espécies frutíferas pouco exploradas, com potencial econômico e social para o Brasil. Revista Brasileira de Fruticultura, Cruz das Almas, v. 9, n. extra, p. 11-22, 1987.

FONSECA, E. T. da. Frutas do Brasil. Rio de Janeiro: 77-78, 1954.

GONÇALVES, N. B. et al. Caracterização física e química dos frutos de cultivares de mangueira (Mangifera indica L.). Ciência e Agrotecnologia, Lavras, v. 22, n. 1, p. 72-78, jan./mar. 1998.

GUIMARÃES, A. D. G.; MOTA, M. G. da C.; NAZARÉ, R. F. R. de. Coleta de germoplasma de bacuri (Platonia insignis Mart.) na Amazônia. I. Microregião Campos do Marajó (Soure/Salvaterra). Belém: Embrapa - CPATU, 1992, 23 p. (Boletim de pesquisa, 132).

INSTITUTO ADOLFO LUTZ. Normas analíticas, métodos químicos e físicos para análise de alimentos. 3. ed. São Paulo: IAL, 1985. v. $1.533 \mathrm{p}$.

LEDERMAN, I. E. et al. Mangaba (Hancornia speciosa Gomes). Jaboticabal: Funep, 2000. 35 p. (Série Frutas Nativas, 2).
MORAES, V. H. de F. et al. Native fruit species of economic potential from the brazilian Amazon. Angewandte Botanik, Goetting, v. 68, n. 1-2, p. 47-52, 1994.

MOURÃO, K. S. M. Morfologia e desenvolvimento de frutos, semente e plântulas de Platonia insignis Mart. (Clusiaceae). Rio Claro, 1992. 90p. Dissertação (Mestrado em Ciências Biológicas), Universidade Estadual Paulista - UNESP.

MOURÃO, K. S. M.; BELTRATI, C. M. Morfologia dos frutos, sementes e plântulas de Platonia insignis Mart (Clusiaceae). I. Aspectos anatômicos dos frutos e sementes em desenvolvimento. Acta Amazônica, Manaus, v. 25, n. 1/2, p. 11-31, 1995.

NAZARÉ, R. F. R. de. Produtos agroindustriais de bacuri, cupuaçu, graviola e açaí, desenvolvidos pela Embrapa Amazônia Oriental. Belém: Embrapa Amazônia Oriental, 2000. 27p. (Embrapa Amazônia Oriental, 41).

PECHNIK, E.; SIQUEIRA, R. de. Dados analíticos sobre 20 frutos brasileiros. Imprensa médica, Rio de Janeiro, v. 26, n. 439, p. 30-44, 1950.

SANTOS, M. do S. S. A. Caracterização física, química e tecnológica do bacuri (Platonia insignis Mart.) e seus produtos. Fortaleza, 1982, 75 p. Dissertação (Mestrado em Tecnologia de Alimentos) Universidade Federal do Ceará.

SOUZA, A. das G. C. de, et al. Fruteiras da Amazônia. Brasília: Embrapa - SPI; Manaus: Embrapa - CPAA, 1996.

SOUZA, V. A. B. de et al. Bacurizeiro (Platonia insignis Mart.). Jaboticabal: Funep, 2000. 72 p. (Série Frutas Nativas, 11).

SOUZA, V. A. B. de et al. Variabilidade de características físicas e químicas de frutos de germoplasma de bacuri da Região Meio-Norte do Brasil. Revista Brasileira de Fruticultura, Jaboticabal - SP, v. 23, n. 3, p. 677-683, 2001.

TEIXEIRA, G. H. de A. Frutos do bacurizeiro (Platonia insignis Mart): caracterização, qualidade e conservação. Jaboticabal, 2000. 106p. Dissertação (Mestrado em Agronomia) - Faculdade de Ciências Agrárias e Veterinárias, Universidade Estadual Paulista.

TEIXEIRA, G. H. de A. et al. Postharvest changes and respiratory pattern of bacuri fruit (Platonia insignis Mart.) at different maturity stages during ambient storage. Acta Amazônica, Manaus, v. 35, n. 1, p. 17-21, 2005.

VILLACHICA, H. et al. Frutales y hortalizas promissoras de la Amazônia. Lima: Tratado de Cooperación Amazônica. Secretaria Pró-Tempore, 1996. p. 152-156 (Publicaciones, 44). 